To cite this article: Maria Ehioghae and Ezinwanyi Madukoma (2020) Health Information Use by Resident Doctors in Lagos State University Teaching Hospital, Ikeja, Lagos State, Nigeria. Information Impact: Journal of Information and Knowledge Management,11:3, 41-50, DOI: /dx.doi.org/10.4314/iijikm.v11i3.5

To link to this article: https://dx.doi.org/10.4314/iijikm.v11i3.5

\title{
Health Information Use by Resident Doctors in Lagos State University Teaching Hospital, Ikeja, Lagos State, Nigeria
}

\author{
${ }^{1}$ Maria Ehioghae and ${ }^{1}$ Ezinwanyi Madukoma \\ ${ }^{1}$ Babcock University, Ogun State, Nigeria
}

\begin{abstract}
The study interrogates health information use by resident doctors in Lagos State University Teaching hospital (LASUTH), Lagos State. Health information has been variously described as the "foundation" for better health, as the "glue" holding the health systems together and as the "oil" keeping the health systems running. It is important for making the right clinical decisions and enhancing professionalism. A survey research design was adopted by the study and the enumeration technique was used to cover all 115 resident doctors that constituted the population. Out of the 115 questionnaire copies administered, 94 copies were returned for data analysis, making the response rate to be $81.7 \%$. The data collected were analyzed using frequency counts and percentages. Findings revealed that the majority of resident doctors in LASUTH have access and use, to a large extent, health information for clinical decision-making. It is, however, recommended that to improve on health information sharing, workshops and seminars on health information should be regularly conducted for resident doctors in LASUTH. This, expectedly, will expose them to new health information trends that will enhance their clinical experience.
\end{abstract}

Keywords Health Information, Information Use, Resident Doctors, Clinical Decision-making

CONTACT Maria Ehioghae and Ezinwanyi Madukoma ehioghaem@babcock.edu.ng Babcock University Teaching Hospital, Babcock University, Ilishan-Remo, Ogun State, Nigeria 


\section{Introduction}

It has been argued that the way doctors think and make clinical decisions is their most critical skill (Croskerry \& Nimmo, 2011). But this cannot be the case if they do not have access to health information. Health information plays a vital role in the clinical decision making of health practitioners in carrying out their duties. As health care providers, doctors need to access relevant, acceptable, and available health information sources to make the right clinical decisions as the cost of the wrong diagnosis could be fatal. Unfortunately, in developing countries like Nigeria, access, and utilization of health information and health care facilities is a perennial challenge (Nwosu, Ogbomo \& Anaehobi, 2013). There are chronic diseases, like cancer and diabetes, which require comprehensive health information for their management because they are not easily cured. As licensed health professionals in the teaching hospitals, resident doctors, particularly, may not be aware of the availability of health information as well as their utilization with regards to these diseases. Information is needed by healthcare workers for efficient and effective clinical management; assessing the extent to which services are meeting the needs and demands of communities. This ensures availability and equitable distribution of health resources and the provision of interventions to reduce disease burdens through prevention strategies.

Health information has been variously described as the "foundation" for better health, as the "glue" holding the health systems together and as the "oil" keeping the health systems running (Nzioka, 2005; Sally, Stansfield, Ndola \& Timothy, 2006). Information use is a prime concept that includes the construction of new knowledge and new meanings, the transformative way of shaping decisions and influencing others, and exchanging of information with people. In other words, sharing information with others is to create new knowledge. Kari (2010) explored this concept by stating that information used by resident doctors includes decision making and problem-solving. Chun, Pierrette, Brian \& Lorna (2008) clarified the concept by stating that information use comes to mind when information acquired by somebody to satisfy an information need is put in use. Instructively, exposure to more information produces greater interest in service delivery, and execution of plans is carried out with relevant, timely, reliable, and trustworthy information.

Like all other professionals, resident doctors utilize information in their medical practice and also for solving clinical problems they experience daily in their practice. Resident doctors' information use and service delivery are based on their specific roles in problem-solving and decision making. Furthermore, aside from ensuring access to relevant sources of knowledge, medical doctors, including the residents, use the information for the medical decision, evidenced-based medicine, to tackle issues on health, manage patient care, new equipment and technologies, to up-date knowledge and support daily practices. For resident doctors to be effective and improve their performance, a relevant, functional information system is very important. In this regard, information use enhances the service delivery of resident doctors.

Health information use reflects on the vital role health information plays in the workplace and society. It refers to the right application of acquired information by resident doctors and other health professionals (Ajuwon, 2006; Nwafor-Orizu \& Nwachukwu, 2014). Information use begins with a feeling stage during which the information user becomes aware of the need to search for information, analyses the importance of the information to the challenges at the moment, and attempts to facilitate effective utilization. Resident doctors' health information use is the capacity to access the right information sources relating to health matters at the right time. The type and complexity of the information will vary depending on the purpose it is meant to serve; whether to be used by a patient deciding where to go for advice or a health professional weighing up the advantages and disadvantages of a particular intervention. In a nutshell, health information use is any information 
that helps someone to understand their health status and make health-related decisions for themselves or their families.

The extent of use of reliable and current health information plays a vital role in the quality of service rendered by resident doctors in the hospitals. Resident doctors are employed to carry out their professional medical practices in line with expectations of quality delivery of services and patient care handling. To perform optimally, healthcare providers need to be able to access and use relevant, acceptable, and available health information sources; this will enable them to make the right clinical decisions. The types of health information used and the knowledge acquired from the various sources are relevant for good medical decision making. A good library system, useful health information sources, adequate information retrieval skills, sufficient computer-based services are necessary for health information use (Ajuwon, 2015; Unegbu, 2019).

Resident doctors use the right health information to manage the patient and perform effectively in their careers. The usefulness of information to medical professionals, especially the resident doctors, may be hampered by the following barriers: poor library system, non-availability of current and relevant sources of information, high cost of acquiring the health-related materials, lack of time and incentive to read and browse. Nwafor-Orizu and Nwachukwu (2014) stated that incompetent computer and internet skills, low motivation associated with poor working conditions, poor internet connectivity, inadequate library opening hours (when the library staff is inconsistent with the opening hours, that is, at such a time the doctors would have loved to use the library and they are not there), non-conducive library environment, non-availability of current health information sources are but few of the factors that could negatively affect the job performance of health professionals. Therefore, having access to credible, trustworthy, and valid health information at the right time, helps the doctor to save the lives of patients.

Kari (2010) explored this concept by stating that health information use by resident doctors contained decision making and problem-solving. In the same vein, Chun, Pierrette, Bria, and Lorna (2008) clarified the concept by stating that information use comes to mind when information acquired by someone to satisfy an information need is put into use. In other words, information use is the modification of a person's knowledge structure.

Ezukwuoke, Okereke, and Onyekwere (2016) asserted that health information use is in the form of ideas and knowledge used for clinical decision making and is of vital importance in the effective and efficient advancement and survival of an individual. The prevailing theory of information use is that human beings use the information to make a vital decision in their environment; they also use the information to improve some structure on the unstructured realities around them. Vickery (2004) observed that man has problems to solve and actions to take, whether he is a scientist, engineer, economist, administrator, or doctor and therefore uses a great variety of information. No matter how well vast he is in his specialty, information that is new to him is continually being used. However, this reveals that no matter how vast a person might think himself to be in the knowledge of his specialty, he uses information daily to be able to handle what he might face as he operates within the specialty.

The study carried out by Nwafor-Orizu and Onwudinjo (2015) showed that doctors' need for health information resources for a range of purposes are not readily met because of a paucity of such materials. In their research findings, Ajegbomogun and Diyaolu (2018) identified knowledge sharing as a predictor of innovation and creativity. The finding also revealed that knowledge sharing helps to find solutions to problems encountered on the job as well as enhances the staff performance skills. Also, the study established a correlation between the availability of library facilities, knowledge sharing, and job performance.

Resident doctors are considered the most valuable assets for every teaching hospital and the performance of every one of them is necessary for the institution's performance in general (Kazemi \& 
Hojatolah, 2012). There is no doubt that different teaching hospitals aim to achieve a high level of job performance where efficiency and effectiveness of the hospital's performance depend on doctors' effectiveness. This shows that achieving the integration and balance within the teaching hospital where they work and growing their creative powers are some of the factors that help doctors to achieve the institution's objectives (Omotunde, 2015).

To achieve high job performance, institutions always strive to get the right set of people at the right place who are capable of delivering effectively and efficiently, completing the work required so that the institution will be able to meet the set goals and objectives. Health information use enhances doctors' medical practice and for them to remain competitive and provide effective health care services in the teaching hospitals they must be equipped with up-to-date knowledge and skills. Job performance depends on both ability and motivation which is the reason why doctors who are performing at high levels within an institution are usually retained. Given the important role health information plays in the life of health practitioners, this study seeks to examine the use of health information by resident doctors in Lagos State University Teaching Hospital (LASUTH), Ikeja, Lagos State.

\section{Objectives of the study}

The objectives of this study are to:

1. identify the types of health information used by resident doctors in Lagos State University Teaching Hospital (LASUTH).

2. ascertain the purposes of health information used by resident doctors in Lagos State University Teaching Hospital (LASUTH).

3. ascertain the extent of health information use by the resident doctors in Lagos State University Teaching Hospital (LASUTH).

\section{Research questions}

To achieve the objectives of the research, the following research questions are asked and answered in this study:

1. What are the types of health information used by resident doctors in Lagos State University Teaching Hospital (LASUTH)?

2. For what purpose are health information used by resident doctors in Lagos State University Teaching Hospital (LASUTH)?

3. To what extent is health information used by resident doctors in Lagos State University Teaching Hospital (LASUTH)?

\section{Methodology}

The study adopted a survey research design that is frequently used to collect data on attitudes and behavior (Akhtar, 2016). The study population comprised all 115 resident doctors in Lagos State University Teaching Hospital (LASUTH), Ikeja, Lagos State. In this study, the total enumeration technique was used to cover the 115 resident doctors in the abovementioned institution. This technique was used by the researcher based on the size and homogeneity of the population and sufficient resources available to carry out this study. Descriptive statistics such as frequencies and percentages were used to analyze the research questions in this study. 


\section{Findings}

This section analyzed the findings of the study as presented below. Out of the 115 questionnaire copies administered, 94 copies were returned for data analysis, making the response rate to be $81.7 \%$.

Table 1: Demographic Variables

\begin{tabular}{|l|l|l|l|}
\hline \multirow{4}{*}{ Demographic variables } & Categories & Total & Percent \\
\hline \multirow{5}{*}{ Gender } & & & \\
\hline & Male & 55 & $58.3 \%$ \\
\cline { 2 - 4 } & Female & 39 & $41.7 \%$ \\
\cline { 2 - 4 } & Total & $\mathbf{9 4}$ & $\mathbf{1 0 0 . 0 \%}$ \\
\hline \multirow{5}{*}{ Marital status } & $25-30 \mathrm{yrs}$ & 16 & $17.2 \%$ \\
\cline { 2 - 4 } & $31-40 \mathrm{yrs}$ & 59 & $62.8 \%$ \\
\cline { 2 - 4 } & $41-50 \mathrm{yrs}$ & 17 & $17.7 \%$ \\
\cline { 2 - 4 } & $51-60 \mathrm{yrs}$ & 2 & $2.3 \%$ \\
\cline { 2 - 4 } & Total & $\mathbf{9 4}$ & $100.0 \%$ \\
\hline & Married & 57 & $61.4 \%$ \\
\cline { 2 - 4 } & Single & 33 & $34.6 \%$ \\
\cline { 2 - 4 } & Separated & 1 & $1.2 \%$ \\
\cline { 2 - 4 } & Widowed & 3 & $2.8 \%$ \\
\cline { 2 - 4 } & Total & $\mathbf{9 4}$ & $\mathbf{1 0 0 . 0 \%}$ \\
\hline Highest level of education & MBBS/MBCHB & 75 & $80.1 \%$ \\
\cline { 2 - 4 } & Masters & 17 & $17.9 \%$ \\
\cline { 2 - 4 } & PhD & 2 & $2.0 \%$ \\
\cline { 2 - 4 } & Total & $\mathbf{9 4}$ & $\mathbf{1 0 0 . 0 \%}$ \\
\hline Designation & Junior resident & 58 & $61.2 \%$ \\
\cline { 2 - 4 } & Senior resident & 36 & $38.8 \%$ \\
\cline { 2 - 4 } & Total & $\mathbf{9 4}$ & \\
\hline
\end{tabular}

Source: Researcher's Field Study, 2020

The results of the study on gender as shown in Table 1 indicate that $55(58.3 \%)$ of the respondents were males while 39 (41.7\%) were females. This finding suggests that there were more male resident doctors in Lagos State University Teaching Hospital (LASUTH), a reflection of gender imbalance to an extent.

It was also revealed that there were more resident doctors in the age brackets of 31-40 years $(62.8 \%)$ than other age groups. This means that resident doctors in the teaching hospitals in LASUTH were relatively very young and vibrant workforce. The finding also reveals that $57(61.4 \%)$ of the participants were married. This finding suggests that resident doctors in LASUTH were sufficiently matured to be married. With regards to the educational qualifications of the respondents, $75(80.1 \%)$ had MBBS/MBChB degrees, followed by Masters' degree holders 17 (17.9\%) and Ph.D. holders 2 (2\%). This finding suggests that the academic qualifications for resident doctors in the LASUTH teaching hospital have a preponderance of MBBS/MBChB degrees as opposed to a Ph.D. This may not necessarily affect the performance of resident doctors since the medical practice is largely professional. In the case of designation, there are more junior residents $(61.2 \%)$ than the senior (38.8\%), indicating that not all residents can move to the upper cadre at the same time because of the required professional examinations. 
Research question 1: What are the types of health information used by resident doctors in Lagos State University Teaching Hospital (LASUTH)?

Table 2: Types of health information used by resident doctors

\begin{tabular}{|c|c|c|c|}
\hline Types of Health Information & & & \\
\hline I use health information on & Frequently & Rarely & Not at all \\
\hline clinical decision- making & $89(94.6 \%)$ & $2(2.2 \%)$ & $3(3.2 \%)$ \\
\hline clinical care of patients & $87(93.0 \%)$ & $2(2.2 \%)$ & $5(4.8 \%)$ \\
\hline how to treat patients & $85(90.8 \%)$ & $3(2.9 \%)$ & $6(6.3 \%)$ \\
\hline patient-related treatments and test & $80(84.9 \%)$ & $5(5.0 \%)$ & $9(10.1 \%)$ \\
\hline general medical knowledge & $78(82.8 \%)$ & $6(6.8 \%)$ & $10(10.4 \%)$ \\
\hline the spread of a particular disease & $77(82.1 \%)$ & $6(6.6 \%)$ & $11(11.3 \%)$ \\
\hline the prevalence of symptoms in a given disease & $75(80.1 \%)$ & $6(6.6 \%)$ & $13(13.3 \%)$ \\
\hline clinical research & $74(78.8 \%)$ & $8(8.1 \%)$ & $12(13.1 \%)$ \\
\hline disease outcome & $75(79.7 \%)$ & $8(8.4 \%)$ & $11(11.9 \%)$ \\
\hline new equipment and technology & $68(72.3 \%)$ & $7(7.5 \%)$ & $19(20.2 \%)$ \\
\hline
\end{tabular}

Respondents were asked to identify the types of health information used in LASUTH. The findings in Table 2 revealed that at least $70.0 \%$ of the resident doctors indicated "Frequently" to all the ten items investigated on the types of health information used in teaching hospitals. This suggests that health information was widely used by resident doctors in LASUTH. Specifically, the findings for the majority of the respondents indicated that information on clinical decision-making (94.6\%) was topmost among types of health information used. Other types of health information used in order of importance include clinical care of patients $(93.0 \%)$; how to treat patients $(91.1 \%)$; patient-related treatments and test $(90.8 \%)$; general medical knowledge $(82.1 \%)$; the spread of a particular disease $(82.8 \%)$; the prevalence of symptoms in a given disease $(80.1 \%)$; clinical research $(78.8 \%)$; disease outcome $(79.7 \%)$ and new equipment and technology (72.3\%). This implies that resident doctors in teaching hospitals in LASUTH regard the use of health information to be significant for their jobs.

Research question 2: For what purpose are health information used by resident doctors in Lagos State University Teaching Hospital (LASUTH)?

Table 3: Purpose of health information use in LASUTH

\begin{tabular}{|c|c|c|c|c|}
\hline Purpose of Health Information & & & & \\
\hline I use information & Very True & True & False & Very False \\
\hline for clinical decision-making & $55(58.2 \%)$ & $36(39.0 \%)$ & $2(1.7 \%)$ & $1(1.1 \%)$ \\
\hline for better practice of specialty & $54(57.4 \%)$ & $33(35.2 \%)$ & $4(3.9 \%)$ & $3(3.5 \%)$ \\
\hline to update knowledge and support daily practices & $55(58.4 \%)$ & $30(32.0 \%)$ & $6(6.8 \%)$ & $3(2.8 \%)$ \\
\hline
\end{tabular}




\begin{tabular}{|l|l|l|l|l|}
\hline for clinical care of patients & $53(56.4 \%)$ & $33(35.1 \%)$ & $4(4.2 \%)$ & $4(4.3 \%)$ \\
\hline for clinical research & $50(53.1 \%)$ & $40(42.2 \%)$ & $3(3.3 \%)$ & $1(1.4 \%)$ \\
\hline for medical practices & $56(59.1 \%)$ & $30(32.4 \%)$ & $6(6.3 \%)$ & $2(2.2 \%)$ \\
\hline $\begin{array}{l}\text { to exercise good judgment about the best course } \\
\text { of action for an individual patient }\end{array}$ & $55(58.4 \%)$ & $29(30.9 \%)$ & $8(8.4 \%)$ & $2(2.3 \%)$ \\
\hline $\begin{array}{l}\text { to offer adequate justification about clinical } \\
\text { decisions }\end{array}$ & $46(48.9 \%)$ & $40(42.8 \%)$ & $3(3.1 \%)$ & $5(5.2 \%)$ \\
\hline $\begin{array}{l}\text { to answer patients' specific questions } \\
\text { to know disease outcome }\end{array}$ & $45(47.6 \%)$ & $41(43.1 \%)$ & $6(6.8 \%)$ & $2(2.5 \%)$ \\
\hline
\end{tabular}

Respondents were asked to indicate the purposes for using health information. Findings from Table 3 revealed that the majority of the respondents use health information to make clinical decisions. This suggests that health information was widely used by resident doctors for clinical decision-making (97.2\%), which was the topmost purpose. Other reasons for using health information among resident doctors in LASUTH were for better practice of specialty (92.6\%); to update knowledge and support daily practices $(90.4 \%)$; for clinical care of patients (91.5\%); for clinical research $(95.3 \%)$; for medical practices $(91.5 \%)$; to exercise good judgment about the best course of action for an individual patient (89.3\%); to offer adequate justification about clinical decisions (91.7\%); to answer patients' specific questions $(90.7 \%)$, and to know disease outcome (84.2\%). This finding may suggest the widespread use of health information among resident doctors in LASUTH.

Research question 3: To what extent is health information used by resident doctors in Lagos State University Teaching Hospital (LASUTH)?

Table 4: Extent of health information use by resident doctors in LASUTH

\begin{tabular}{|c|c|c|c|c|}
\hline Extent of Health Information & & & & \\
\hline I use health information & $\begin{array}{l}\text { Very Great } \\
\text { Extent }\end{array}$ & Great Extent & Some Extent & Small Extent \\
\hline for clinical decision- making & $42(45.1 \%)$ & $40(42.3 \%)$ & $11(11.3 \%)$ & $1(1.3 \%)$ \\
\hline for clinical care of patients & $39(41.4 \%)$ & $38(40.9 \%)$ & $13(13.1 \%)$ & $4(4.6 \%)$ \\
\hline $\begin{array}{l}\text { to offer adequate justification about clinical } \\
\text { decisions }\end{array}$ & $38(40.8 \%)$ & $39(41.5 \%)$ & $10(10.6 \%)$ & $7(7.1 \%)$ \\
\hline $\begin{array}{l}\text { to exercise good judgment about the best course of } \\
\text { action for an individual patient }\end{array}$ & $41(43.1 \%)$ & $34(36.4 \%)$ & $14(14.9 \%)$ & $5(5.6 \%)$ \\
\hline for professional examinations & $42(44.2 \%)$ & $34(36.0 \%)$ & $13(13.9 \%)$ & $5(5.9 \%)$ \\
\hline for clinical research & $39(42.0 \%)$ & $40(42.6 \%)$ & $10(10.9 \%)$ & $4(4.5 \%)$ \\
\hline for medical practices & $38(40.2 \%)$ & $37(39.9 \%)$ & $13(13.4 \%)$ & $6(6.5 \%)$ \\
\hline to answer patients' specific questions & $37(38.9 \%)$ & $41(44.1 \%)$ & $12(12.7 \%)$ & $4(4.3 \%)$ \\
\hline to prescribe drugs & $34(35.9 \%)$ & $32(34.1 \%)$ & $18(19.2 \%)$ & $10(10.8 \%)$ \\
\hline to know disease outcome & $35(37.2 \%)$ & $34(36.3 \%)$ & $16(16.6 \%)$ & $9(9.9 \%)$ \\
\hline
\end{tabular}


Table 4 shows the extent of health information used by resident doctors in Lagos State University Teaching Hospital (LASUTH). The majority of resident doctors use health information for clinical decision-making (87.4\%). Other health information that indicates the extent of use are: for clinical care of patients (82.3\%); offering adequate justification about clinical decisions (82.3\%); exercising good judgment about the best course of action for an individual patient (79.5\%); professional examinations $(80.2 \%)$; clinical research $(84.6 \%)$; medical practices $(80.1 \%)$; answering patients' specific questions (83\%); prescribing drugs $(70 \%)$ and knowing disease outcome $(73.5 \%)$. The result showed that health information was mostly utilized by resident doctors for clinical purposes in teaching hospitals in LASUTH.

\section{Discussion of findlings}

The findings revealed that resident doctors in LASUTH place high regard for the use of health information and believe that it is significant for their jobs. This is in line with a study carried out by Nwafor-Orizu and Nwachukwu (2014) which shows that doctors place a high premium on health information but the need for this information is not readily met because of the paucity of information resources. Specifically, the study revealed that most resident doctors use the information on clinical decision-making which tallies with the findings of earlier research carried out by Ezukwuoke, Okereke and Onyekwere (2016). Since clinical decision-making is of vital importance in handling health conditions and may determine the survival of an individual, information on how to make such decisions is paramount.

In respect to research question two that interrogates the purpose of health information use, the findings show that most resident doctors use the information for clinical decision-making and better practice of the specialty. This is in congruence with the findings of Onyi and Titus (2018) and Vickery (2004) who observed that no matter how well vast they think of themselves in their specialty, humans generally use a great variety of information that is new to them. Doctors particularly would need to update their knowledge to keep up with the pace of new trends in their field. In the same vein, Kari (2010) explored the concept of health information and concluded that information used by resident doctors contained decision making and problem-solving.

Finally, research question three focuses on the extent of health information use by resident doctors in teaching hospitals. As to the extent of the use of health information, the findings reveal that most of the resident doctors use health information to make clinical decisions on a larger scale than other uses. Though the findings reveal that most resident doctors use the information for clinical decision-making to a large extent, it is not always the case that such information will be used even when they are available. This stands in contrast to the findings made by Ajegbomogun and Diyaolu (2018) that information use is directly a function of its availability. Given that availability of information is important to information use, their findings did not reckon with intervening variables, particularly in the case of doctors whose work schedules are often too tight to enable them to give the needed attention to patients.

\section{Conclusion and recommendations}

There are a variety of ways resident doctors can use health information to enhance their clinical experience. This may include health information on clinical decision-making, clinical care of patients, and general medical knowledge. Conclusively, the availability and wide use of health information by resident doctors in LASUTH is encouraging and thus may enhance their productivity. The availability of health information is, however, not a guarantee that they will always be used. Intervening variables such as workloads or too tight work schedules of resident doctors may sometimes hamper the use of available information to enhance their clinical practice. It is, therefore, recommended that: 
1. The management of government teaching hospitals in Lagos State University Teaching Hospital (LASUTH) should ensure that resident doctors are not overloaded in their work schedules to further enhance their ability to adequately deploy existing health information for clinical practices.

2. Efforts should be made by resident doctors and hospital management, alike, to enhance the dissemination of health information through collaborative platforms to enhance the sharing of knowledge on different areas of doctor's specialty.

3. Since knowledge is power, resident doctors should not only be exposed to training sessions, conferences, and workshops to apprise them with modern trends in health information, they can also be encouraged to enroll in Ph.D. programs.

\section{References}

Ajegbomogun, O. F. \& Diyaolu, O. B. (2018). Availability of library facilities, knowledge sharing as determinants of the job performance of library staff in Southwest Nigeria. Library Philosophy and Practice (e-journal). Retrieved from http://digitalcommons.unl.edu/libphilprac/1784.

Ajuwon, G. A. (2015). Internet accessibility and use of online health information resources by doctors in training healthcare institutions in Nigeria. Library Philosophy and Practice (ejournal). Retrieved from http://digitalcommons.unl.edu/libphilprac/1258

Ajuwon, G. A. (2006). Use of the internet for health information by physicians for patient's care in a teaching hospital in Ibadan, Nigeria. Biomedical Digital Library, 12 (3), 23-31.

Akhtar, M. I. (2016). Research Design. Research in Social Science: Interdisciplinary Perspectives, 68-84. Available at: http://dx.doi.org/10.2139/ssrn.2862445.

Croskerry, P. \& Nimmo, G. R. (2011). Better clinical decision making and reducing diagnostic error. J R Coll Physicians Edinb, 41:155-62.

Chun, W. C. Pierrette, B. Brian, D. \& Lorna, H. (2008). Information culture and information use: an exploratory study of three information needs and information-seeking behavior and use of information resources organizations. Journal of American Society for information science and technology, 5, 792-804.

Dosa, M. (2000). Issues of information utilization and dissemination in technical aid projects. Syracuse: Syracuse University.

Epstein, R. M., \& Hundert, E. M. (2002). Defining and assessing professional competence. The Journal of the American Medical Association, 287 (2), 226-235.

Ezukwuoke, N. E. Okereke, C. \& Onyekwere, A. (2016). Information needs and sources for Ebola virus disease among the staff of college of medicine in Enugu, Nigeria. Journal of Medical Library Association, 3 (1), 46-50.

Kari, J. (2010). Diversity in the concepts of information use. Information Research,15 (3),14-21. 
Kazemi, S. J. \& Hojatolah, M. (2012). Effective Communication Skills on Job

Stress. Journal of Educational Management, 3, 63-80.

Nwafor-Orizu, O. E. \& Onwudinjo, O. T. U. (2015). Availability and use of health information resources by doctors in teaching hospitals in southeast Nigeria. Information and Knowledge Management, 5 (9), 102-108.

Nwafor-Orizu, O. E. \& Nwachukwu, V. (2014). Library intervention on resident doctors' use of online health information resources: Impact assessment. Journal of Medical Library Association, 2 (1 \&2): 10-21.

Nwosu, O., Ogbomo, E. F., Anaehobi, E. S. (2013). Health information availability and utilization by medical practitioners for chronic disease management in central hospitals, Warri-Delta State. Journal of Pharmacy, 3 (3), 18-23.

Nzioka M. S. (2005). Health information generation and utilization for informed decisionmaking inequitable health service management: the case of Kenya partnership for health program. International Journal for Equity in Health, 4 (1), 8.

Omotunde, O. I. (2015). Talent management, self-efficacy and job performance of librarians in university libraries in South-west Nigeria. Ph.D. Thesis (Unpublished), Babcock University, Ilishan-Remo, Ogun State.

Onyi, T. \& Titus, R. (2018). The utilization of internet for health information among pioneer medical students in a Nigerian University. World Journal of Pharmaceutical and Medical Research, 4 (3), 121-131.

Sally, K., Stansfield, J. \& Walsh, N. P. (2006). Information to improve decision making for health, disease control priorities in developing countries. New York: Oxford University Press.

Unegbu, V. E. (2019). Information needs of teachers. In V. E. Unegbu (Ed.), Information for Diverse User Groups. Lagos: Jamiro Press Link.

Vickery, B. C. (2004). Techniques of information retrieval. London: Butterworth 